\title{
IgG4-related Lung Disease with Organizing Pneumonia Effectively Treated with Azathioprine
}

\author{
Yasutaka Onishi, Tetsuji Kawamura, Ryogo Kagami, \\ Yasuharu Nakahara and Mochiduki Yoshiro
}

\begin{abstract}
Immunoglobulin (Ig)-G4-related disease is a multi-organ disease that may affect the lung. We herein describe a patient with IgG4-related lung disease (IgG4-RLD) who was radiologically and pathologically diagnosed with organizing pneumonia. He was successfully treated with a combination of prednisolone (PSL) and azathioprine (AZA), and his clinical course has been uneventful since tapering off PSL. This is a rare case of IgG4-RLD manifesting as organizing pneumonia, and, to our knowledge, this is also the first case showing the effectiveness of AZA in treating IgG4-RLD.
\end{abstract}

Key words: IgG4-related lung disease, IgG4-related pulmonary disease, IgG4-related disease, organizing pneumonia, azathioprine, prednisolone

(Intern Med 53: 2701-2704, 2014)

(DOI: 10.2169/internalmedicine.53.2564)

\section{Introduction}

Since the first report on autoimmune pancreatitis (AIP) in 2001, IgG4-related disease (IgG4-RD) has been recognized as a form of systemic sclerosing disease (1). Pulmonary manifestations of IgG4-RD include inflammatory pseudotumor and interstitial pneumonia, but other lung manifestations may also occur (2). We herein describe a patient with IgG4-related lung disease (IgG4-RLD) presenting with organizing pneumonia. This patient relapsed during prednisolone (PSL) monotherapy but was effectively treated with a combination of PSL plus azathioprine (AZA).

\section{Case Report}

A 68-year-old man was referred to our department in April 2007 with swelling of the mediastinal lymph nodes, a thin tumor around the thoracic vertebrae, and an elevated serum $\mathrm{IgG}$ concentration $(4,730 \mathrm{mg} / \mathrm{dL})$. His previous medical history included a diagnosis of diabetes at age 63 years, and diagnoses of hyperuricemia, atrial fibrillation, and dilated cardiomyopathy at age 68 years. The examination of a lymph node biopsy taken under mediastinoscopy showed only non-specific granulomatous changes, and no definite diagnosis was reached. Although the patient was not treated, the mediastinal lymph nodes decreased in size and his serum IgG level was reduced. In 2011, however, he began to feel dyspnea on exertion. A chest computed tomography (CT) revealed an infiltrative shadow with an air bronchogram in the lower lobes of both lungs (Fig. 1), and his serum IgG and IgG4 concentrations were again elevated. He was therefore admitted to our hospital. The patient was in good physical condition upon admission, with no evidence of crackles or heart murmur. The oxygen saturation was 97\% (room air). The results of the respiratory function test were normal, with a vital capacity (VC) of $3.02 \mathrm{~L}(92.6 \%$ predicted) and a forced expiratory volume in one second (FEV1) of $2.32 \mathrm{~L}$ (98.3\% predicted). His serum $\mathrm{IgG}(3,215$ $\mathrm{mg} / \mathrm{dL}$; normal range $870-1,700 \mathrm{mg} / \mathrm{dL})$ and $\operatorname{IgG} 4(1,260$ $\mathrm{mg} / \mathrm{dL}$; normal range $<105 \mathrm{mg} / \mathrm{dL}$ ) concentrations were markedly elevated. His serum $\operatorname{IgA}(182 \mathrm{mg} / \mathrm{dL})$ and $\operatorname{IgM}$ $(69 \mathrm{mg} / \mathrm{dL})$ concentrations were in the normal range. We also observed elevated serum concentrations of soluble interleukin (IL)-2 receptor $(1,292 \mathrm{U} / \mathrm{mL}$; normal range $<519 \mathrm{U} /$ $\mathrm{mL})$, Krebs von den Lungen-6 (KL-6) $(591 \mathrm{U} / \mathrm{mL}$; normal range $<500 \mathrm{U} / \mathrm{mL}$ ), brain natriuretic peptide (BNP) $(156 \mathrm{pg} /$ $\mathrm{mL}$; normal range $<18.4 \mathrm{pg} / \mathrm{mL})$, hemoglobin $(\mathrm{Hb}) \mathrm{A} 1 \mathrm{c}$ 

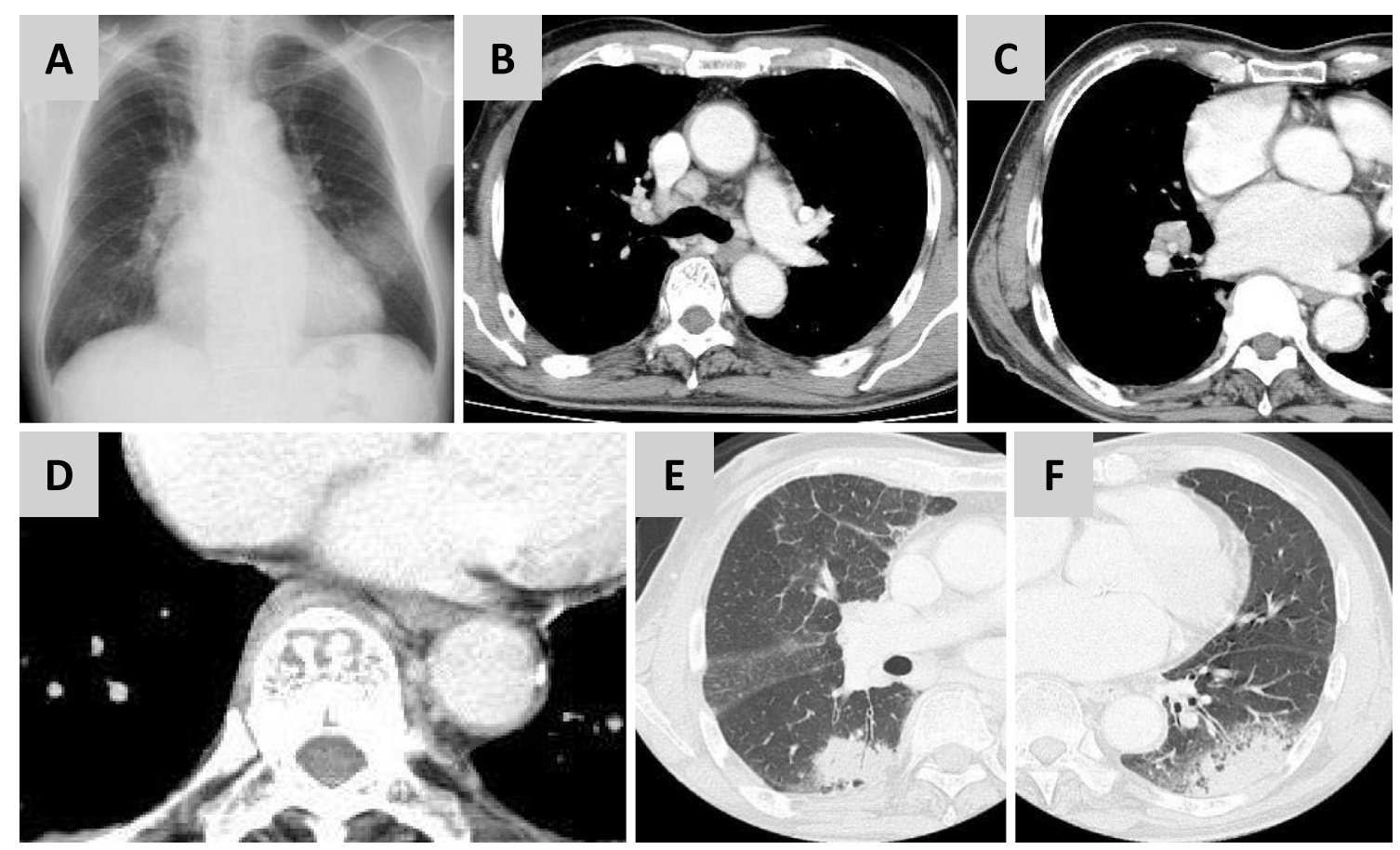

Figure 1. (A) The chest $\mathrm{X}$-ray upon admission showed widening of the right hilum, consolidation in the left lung field and cardiomegaly. (B, C) The chest CT showed swelling of mediastinal and right hilar lymph nodes. (D) The chest $\mathrm{CT}$ revealed a posterior mediastinal thin tumor around the thoracic vertebrae. (E, F) High-resolution CT revealed consolidation with air bronchogram in both lower lobes, and thickening of bronchial vascular bundles and interlobular septa in both the middle and lower lobes.

(6.5\%; normal <5.9\%), and IL-6 $(6.9 \mathrm{pg} / \mathrm{mL}$; normal $<4.0$ $\mathrm{pg} / \mathrm{mL})$, although his serum angiotensin-converting enzyme (ACE) (15.8 U/L) was in the normal range (8.3-21.4 U/L). He was negative for a variety of autoimmune antibodies, including anti-nuclear and anti-cyclic citrullinated peptide (CCP) antibodies. A chest X-ray (Fig. 1A) showed widening of the right hilum, infiltrative shadows in the lower field of the left lung and cardiomegaly. Chest CT revealed consolidation with air bronchogram in the right lower lobe $S^{6}$ and left lower lobe, thickening of bronchial vascular bundles and interlobular septa in both the middle and lower lobes, mediastinal lymph node swelling, and a posterior mediastinal thin tumor around the thoracic vertebrae (Fig. 1).

The collection rate of bronchoalveolar lavage fluid at the right $\mathrm{S}^{8}$ bronchus was $40 \%$, with a total cell count of $1.9 \times$ $10 \% \mathrm{~mL}$ and almost normal cell fractions: $86 \%$ macrophages, $9 \%$ lymphocytes, and $2 \%$ eosinophils, and a CD4/CD8 ratio of 1.4. Video-assisted thoracoscopic segmentectomy of the right $S^{6}$ was performed, and pathologically ill-defined patchy lesions were observed at a low power field (Fig. 2). These patchy lesions consisted of organization in the airway cavity, lymphocytic infiltrates, plasma cells and a few eosinophils around alveolar septal walls and small blood vessels, and luminal exudates in the alveolar space. Immunostaining showed an increase in IgG-positive cells, with an IgG4/IgG ratio exceeding $60 \%$, and no monoclonality in the light chain. The polymerase chain reaction (PCR) analysis revealed no monoclonal rearrangement in the immunoglobulin heavy chain gene or T-cell receptor $\gamma$-chain gene.

These findings suggested a diagnosis of IgG4-RLD. The patient was treated with PSL (30 mg/day), which improved his dyspnea on exertion, chest CT findings, and IgG and IgG4 concentrations (Fig. 3). PSL was tapered, but eight months later, while the patient was receiving PSL $(5 \mathrm{mg} /$ day), multiple infiltrative shadows appeared in both lungs. Increasing PSL was temporarily effective, and a dose of 10 $\mathrm{mg} /$ day was inadequate. Treatment with PSL (20 mg/day) plus methotrexate (MTX) $5 \mathrm{mg} /$ week was also ineffective. The patient was therefore treated with a combination of PSL (20 mg/day) plus AZA (50 mg/day), and marked improvement was observed within several weeks (Fig. 3). His clinical course thereafter has been uneventful, even after tapering off PSL.

\section{Discussion}

IgG4-RD is a disease involving multiple organs and includes AIP. Several patients with IgG4-RD were found to have interstitial pneumonia or other pulmonary lesions (3). Pulmonary parenchymal lesions of IgG4-RLD have been classified as "nodules or masses" or as "interstitial lung disease" (2). The nodules or masses are thought to correspond in part to conventional inflammatory pseudotumors, whereas interstitial lung disease has been defined mainly as lymphoproliferative lesions involving the peribronchial interstitium or interlobular septum, but may also include nonspe- 

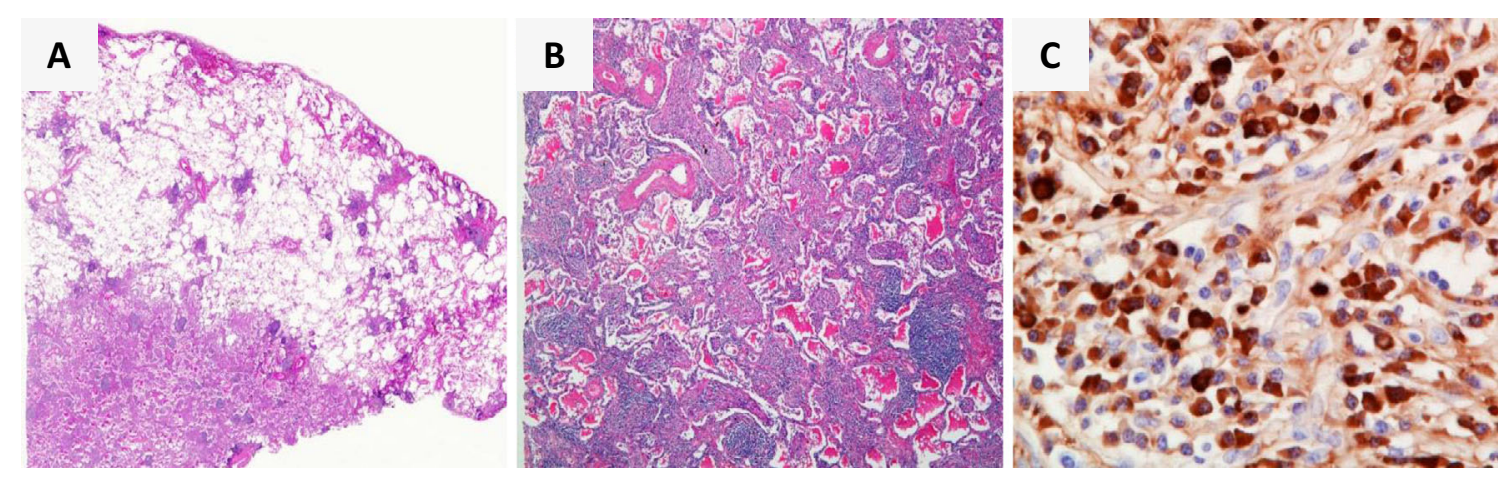

Figure 2. Histopathological findings obtained by video-assisted thoracoscopic surgery at right $\mathrm{S}^{6}$. (A, B) Low magnification view shows infiltration of lymphocytes, plasma cells, and a few eosinophils along with bronchial vascular bundles and the interlobular septa. Intra-alveolar organization with the proliferation of plasma cells is observed. The alveolar spaces are filled with luminal exudate (Hematoxylin and Eosin staining. A, 1× B, 4×). (C) Immunohistochemistry staining demonstrated infiltration of the IgG4-positive plasma cells $(20 x)$.

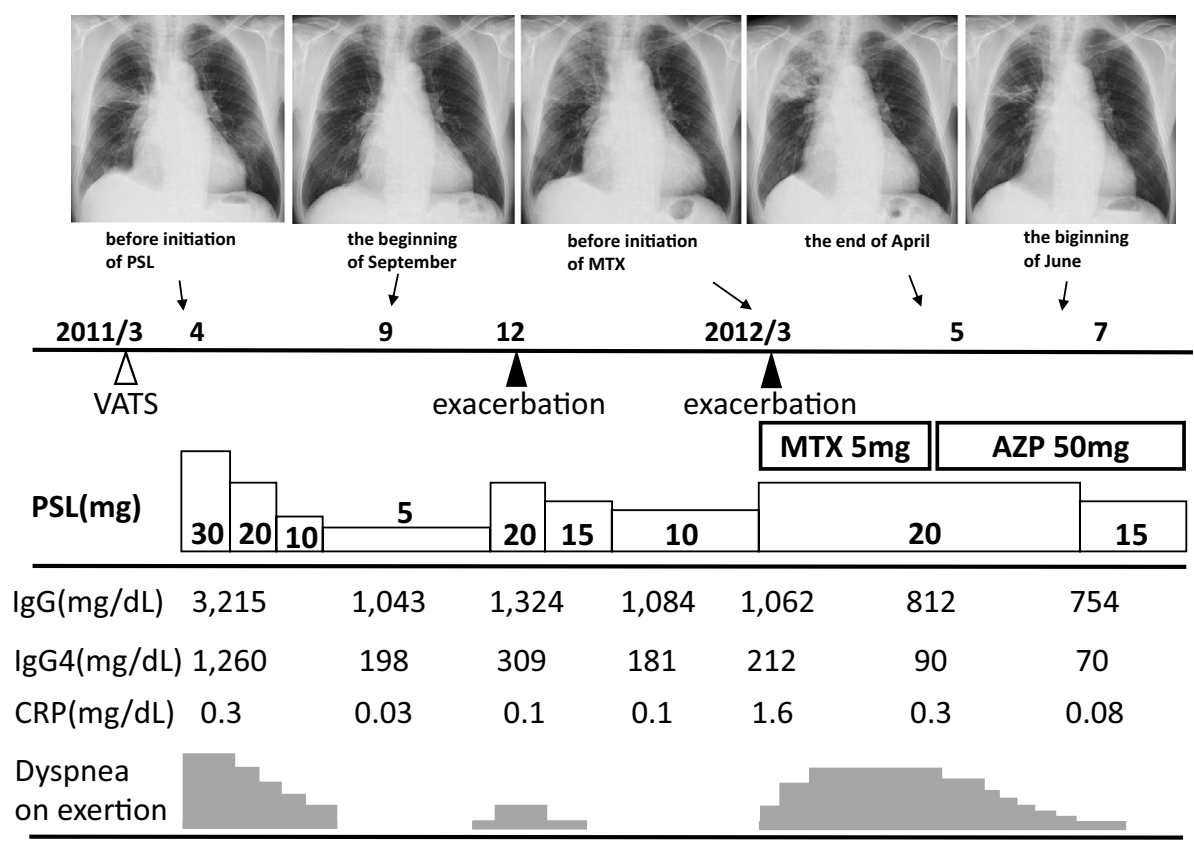

Figure 3. The clinical course.

cific interstitial pneumonia (NSIP)-like or organizing pneumonia-like lesions (4). The radiologic and pathologic examinations suggested that our patient had IgG4-related organizing pneumonia. Because this patient lacked typical extrapulmonary lesions such as AIP, other than a tumor around the thoracic vertebrae, it was important to differentiate $\mathrm{IgG}$ 4-related organizing pneumonia from other diseases that exhibit organizing pneumonia. Chronic eosinophilic pneumonia, bacterial pneumonia, and drug-induced pneumonia were unlikely based on the clinical course. Although Sjögren syndrome may mimic IgG4-RD, our patient did not fulfill the diagnostic criteria for Sjögren syndrome. In addition, he did not have rheumatoid arthritis, which is occasionally associated with organizing pneumonia. Multicentric Castleman's disease (MCD) partially overlaps IgG4-RD, and differentiation between the two is sometimes difficult (5). MCD, however, often exhibits abnormal findings associated with in- flammation, such as elevated C-reactive protein (CRP), hypoalbuminemia, anemia, and hypocholesterolemia (6). Based on the clinical course observed in our patient, MCD was an unlikely diagnosis.

High-resolution CT findings in patients with IgG4-RLD have been classified into four types: solid nodular, roundshaped ground glass opacity, alveolar interstitial, and bronchovascular types (7). However, the infiltrative type, as in our patient, has not been clearly described. There have been several case reports of patients with IgG4-RD exhibiting organizing pneumonia (8-12). However, pulmonary lesions have not been included in the diagnostic criteria for IgG4$\mathrm{RD}$ (13). It is therefore necessary to evaluate additional patients with IgG4-related pulmonary disease to establish the diagnostic criteria for this condition.

IgG4-RD generally responds well to steroid therapy, which is often started at an intermediate dose of $30 \mathrm{mg} /$ 
day (2). After steroid tapering, however, the disease may relapse, with relapse rates of $32 \%$ within six months and $52 \%$ and $92 \%$ within 1 and 3 years, respectively (14). We combined a steroid with AZA, a drug shown to be effective in treating AIP and IgG4-associated cholangitis $(15,16)$.

It is known that the effectiveness of corticosteroids is usually evaluated according to the improvement of clinical symptoms and radiological findings, and serological markers may not reflect the condition of IgG4-RD (14). In the present case, MTX was considered to be ineffective because the patient's clinical symptoms and radiographic findings did not improve. However after the administration of AZA, both the symptoms and radiological findings quickly improved, and no recurrence has been observed despite tapering of PSL to $10 \mathrm{mg} /$ day. We thereby speculate that improvement of the disease was due to the effect of AZA.

The action mechanism of AZA has not been fully elucidated due to complex metabolic pathways and the genetic polymorphisms in metabolizing enzymes (17). AZA is nonenzymatically rapidly converted to 6-MP, acting as a purine analogue and an inhibitor of DNA and RNA synthesis. By this process, the proliferation of both $\mathrm{T}$ cells and $\mathrm{B}$ cells are suppressed, and AZA shows immunosuppressive and anti-inflammatory effects (18).

Conversely, the anti-inflammatory effect of MTX is mainly due to the suppression of adhesion and activation of $\mathrm{T}$ cells. It has been suggested that the ineffectiveness of MTX and responsiveness to AZA treatment were due to the involvement of B cells in IgG4-RD (19).

The combinations of steroids with cyclosporine, AZA, mycophenolate mofetil, rituximab, and MTX have also been found effective in patients with $\operatorname{IgG} 4-\operatorname{RD}(15,16,20-22)$, with cyclosporine reported to be the only agent effective in treating pulmonary lesions (11). Furthermore, we were unable to find any reports discussing the characteristics of steroid-resistant IgG4-RLD. Further examination of additional patients is needed to select the appropriate immunosuppressants and determine criteria for their use in IgG4RLD patients.

We described a patient with IgG4-RLD who exhibited organizing pneumonia and was successfully treated with a combination of PSL and AZA. The assessment of additional patients and establishment of diagnostic criteria for IgG4RLD are necessay to facilitate the diagnosis and treatment of this disease.

The authors state that they have no Conflict of Interest (COI).

\section{References}

1. Hamano H, Kawa S, Horiuchi A, et al. High serum IgG4 concentrations in patients with sclerosing pancreatitis. $\mathrm{N}$ Engl $\mathrm{J}$ Med 344: 732-738, 2001.
2. Ryu JH, Sekiguchi H, Yi ES. Pulmonary manifestations of immunoglobulin G4-related sclerosing disease. Eur Respir J 39: 180186, 2012.

3. Taniguchi $\mathrm{T}$, Ko M, Seko $\mathrm{S}$, et al. Interstitial pneumonia associated with autoimmune pancreatitis. Gut 53: 770-771, 2004.

4. Takato H, Yasui M, Ichikawa $Y$, et al. Nonspecific interstitial pneumonia with abundant IgG4-positive cells infiltration, which was thought as pulmonary involvement of IgG4-related autoimmune disease. Intern Med 47: 291-294, 2008.

5. Sato Y, Kojima M, Takata K, et al. Systemic IgG4-related lymphadenopathy: a clinical and pathologic comparison to multicentric Castleman's disease. Mod Pathol 22: 589-599, 2009.

6. Peterson BA, Frizzera G. Multicentric Castleman's disease. Semin Oncol 20: 636-647, 1993.

7. Inoue D, Zen Y, Abo H, et al. Immunogloblin G4-related lung disease: CT findings with pathologic correlations. Radiology 251: 260-270, 2009.

8. Duvic C, Desrame J, Lévêque C, Nedelec G. Retroperitoneal fibrosis, sclerosing pancreatitis and bronchiolitis obliterans with organizing pneumonia. Nephrol Dial Transpl 19: 2397-2399, 2004.

9. Suzuki H, Watanabe M, Ara T, et al. Immunogloblin G4-related lung disease accompanied by organizing pneumonia. Intern Med 52: 2105-2111, 2013.

10. Taniguchi T, Hamasaki A, Okamoto M. A case of suspected lymphocytic hypophysitis and organizing pneumonia during maintenance therapy for autoimmune pancreatitis associated with autoimmune thrombocytopenia. Endocr J 53: 563-566, 2006.

11. Kobayashi H, Shimokawaji T, Kanoh S, et al. IgG4-positive pulmonary Disease. J Thorac Imaging 22: 360-362, 2007.

12. Shrestha B, Sekiguchi H, Colby TV, et al. Distinctive pulmonary histopathology with increased IgG4-positive plasma cells in patients with autoimmune pancreatitis: report of 6 and 12 cases with similar histopathology. Am J Surg Pathol 33: 1450-1462, 2009.

13. Umehara H, Okazaki K, Masaki Y, et al. Comprehensive diagnostic criteria for IgG4-related disease (IgG4-RD), 2011. Mod Rheumatol 22: 21-30, 2012.

14. Kawano M, Yamada K. Treatment of IgG4-related disease. Curr Immunol Rev 7: 246-251, 2011

15. Ghazale A, Chari ST, Zhang L, et al. Immunogloblin G4associated cholangitis: clinical profile and response to therapy. Gastroenterology 134: 706-715, 2008.

16. Raina A, Yadav D, Krasinskas AM, et al. Evaluation and management of autoimmune pancreatitis: experience at a large US center. Am J Gastroenterol 104: 2295-2306, 2009.

17. Gearry RB, Barclay ML. Azathioprine and 6-mercaptopurine pharmacogenetics and metabolite monitoring in inflammatory bowel disease. J Gastroenterol Hepatol 20: 1149-1157, 2005.

18. Malamud D, Gonzalez EM, Chiu H, et al. Inhibition of cell proliferation by Azathioprine. Cancer Res 32: 1226-1229, 1972.

19. Johnston A, Gudjonsson JE, Sigmundsdottir H, Ludviksson BR, Valdimarsson $\mathrm{H}$. The anti-inflammatory action of methotrexate is not mediated by lymphocyte apotosis, but by the suppression of activation and adhesion molecules. Clin Immunol 114: 154-163, 2005.

20. Sandanayake NS, Church NI, Chapman MH, et al. Presentation and management of post-treatment relapse in autoimmune pancreatits/Immunogloblin G4-associated cholangitis. Clin Gastroenterol Hepatol 7: 1089-1096, 2009.

21. Khosroshahi A, Bloch DB, Deshpande V, Stone JH. Rituximab therapy leads to rapid decline of serum IgG4 levels and prompt clinical improvement in IgG4-related systemic disease. Arthritis Rheum 62: 1755-1762, 2010.

22. Bosco JJ, Suan D, Varikatt W, Lin MW. Extra-pancreatic manifestations of IgG4-related systemic disease: a single-centre experience of treatment with combined immunosuppression. Intern Med J 43: 417-423, 2013.

(C) 2014 The Japanese Society of Internal Medicine http://www.naika.or.jp/imonline/index.html 